\title{
The Social Axioms of Populism: Investigating the Relationship Between Culture and Populist Attitudes
}

\author{
Waleed A. Jami ${ }^{1}$, Markus Kemmelmeier ${ }^{1}$
}

[1] Interdisciplinary Social Psychology Ph.D. Program, University of Nevada, Reno, NV, USA.

Journal of Social and Political Psychology, 2021, Vol. 9(2), 438-455, https://doi.org/10.5964/jspp.7295

Received: 2020-11-01 • Accepted: 2021-06-18 • Published (VoR): 2021-09-09

Handling Editor: Fouad Bou Zeineddine, University of Innsbruck, Innsbruck, Austria

Corresponding Author: Waleed A. Jami, Interdisciplinary Social Psychology Ph.D. Program, University of Nevada, Reno, Mail Stop 1300, Reno, Nevada (United States). E-mail: wjami@nevada.unr.edu

Supplementary Materials: Materials [see Index of Supplementary Materials]

\begin{abstract}
Populism is on the rise with various movements having electoral breakthroughs. Most social-science research on populism has focused primarily on party tactics and rhetoric, and a definition for the term itself; only recently has populism emerged as a psychological construct. We contribute to this growing literature with two studies $(n=456$ and $n=5,837)$ that investigated the cultural worldviews underpinned in populist attitudes. Using the social axioms model, an etic framework for assessing people's generalized social expectations, we linked populist attitudes to universal dimensions of culture. We found that higher levels of social cynicism and social flexibility, and to a lesser extent, lower levels of fate control and reward for application predicted populist attitudes. These findings indicate that people who endorse populist attitudes, across a range of contexts, are cynical regarding the social world, believe in alternative solutions to social dilemmas, but may also perceive a world that is difficult to control and potentially unfair. The discussion focuses on the cultural forces that may drive or facilitate populist attitudes across context and time.
\end{abstract}

\section{Keywords}

populism, populist attitudes, culture, social axioms, multi-level modeling, democracy

\section{Non-Technical Summary}

\section{Background}

Populist movements and populist parties have grown considerably across the world, becoming a prominent political force in many nations. Populism can emerge in different parts of the world like the U.S., Brazil, Philippines, Spain, Poland or India, and it may be associated with different political ideologies (e.g., left-wing versus right-wing). Regardless of national context or ideology, all populist movements emphasize the importance of "the people," and the opposition of "the establishment" or "the elite," which they view as pursuing its own interests, and not the interests of the common people. Whereas some scholars argue that economic malaise is responsible for a rise in populism, researchers increasingly focus on culture, and the cultural conditions that enable populist movements. To date, we know very little about if there are any cultural norms and values that are prominent among supporters of populism, or which make people receptive to populist ideas. 


\section{Why was this study done?}

This research was conducted to examine the cultural underpinnings of populism common among its supporters. We used the social axioms framework, an etic or universal set of cultural dimensions to find the link between culture and populist attitudes. The social axioms represent people's and societies' general expectations of the social world which are also more concrete than norms and values.

\section{What did the researchers do and find?}

We present data from two survey studies. In Study 1, close to 500 U.S. college students responded to questions about populist attitudes and social axioms. We found that people who support populist ideas were highly cynical regarding others, but they were also flexible and willing to look outside of mainstream politics for solutions. Populists were also more likely to feel they have little control of their social world, but they also believed that they were part of a unified or homogeneous group of people, which likely improved their sense of control.

In Study 2, close to 6,000 students from over 33 countries answered questions tapping populist attitudes and social axioms. We replicated our Study 1 findings in different cultural contexts ranging from Bangladesh to the U.S. We also found that people who believed the social world to be unfair or unmeritocratic held populist attitudes. Overall, the cultural underpinnings of populism are relatively consistent across both cultural contexts and the eight-year span between our two studies.

\section{What do these findings mean?}

These findings highlight the importance of culture as an important force in politics. Populism, itself has been documented as a subculture within broader society. These findings may indicate that populist subcultures, regardless of the society in which they exist, share many common values and ideas. Thus, it could also be possible that social issues such as globalization, might give rise to populist ideas regardless of which country it occurs. Finally, these findings may also indicate that if one intervention was used to reduce populist sentiments in one country or culture, it may work in other contexts as well.

Populism is a prominent political force around the world. Across Europe, Asia, and the Americas, populists have steadily increased representation in parliaments and held presidential roles. The breakthrough of populism into mainstream politics began during the 1980s and 1990s starting with the radical right parties in Europe (Betz, 1994) and have shown little signs of slowing down in contemporary politics (Norris \& Inglehart, 2019). Modern democracies now have populist parties across the political spectrum, notably from the radical poles (Rooduijn \& Akkerman, 2017). In contemporary political research, the dominant framework for understanding and conceptualizing populism stems from the ideational approach, which suggests that all forms of populism share two common core ideas (Hawkins \& Rovira Kaltwasser, 2017). First, those with populist sentiments believe in the separation of society into two groups - the people and the elite (Mudde, 2004), and second, the will of the people (volonté générale) must be the central focus in politics. Implied in these two core elements is the Manichaean view - that the people are good and virtuous whereas the elite are dishonest and corrupt, and that majoritarian politics, even at the expense of civil liberties, should not be denied (Pappas, 2013).

Much of the research on populism focused on the tactics and success of political parties or leaders and developing an adequate definition for the term (Akkerman, Mudde, \& Zaslove, 2014). Thus, populist attitudes are a new domain of inquiry in the social sciences (see Rooduijn, 2019), and populism scholars have called for more interdisciplinary work with social and political psychology (Abromeit, 2017; Rensmann, 2017). Recently, a burgeoning interdisciplinary literature has linked populist attitudes with psychological characteristics like social values (Norris \& Inglehart, 2019), personality traits (Vasilopoulos \& Jost, 2020), and collective narcissism (Marchlewska et al., 2018).

In this research, our aim is to contribute to this literature by establishing the association between populist attitudes and culturally-shared beliefs. Specifically, we argue that individual receptivity to populist attitudes is rooted in people's generalized social beliefs about the world. Relying on Leung and Bond's (2008) social axioms' framework, we demonstrate the relationship between shared cultural assumptions to populist attitudes. Study 1 investigated the relationship between social axioms to populist attitudes within a U.S. college sample. Study 2 replicated the results for populist attitudes across 33 countries and examined the link between populist attitudes and country-level social axioms. 


\section{Defining Populism}

Populism, as an ideology, presumes there are two opposing groups in society: the people and the elite. The people are characterized as a homogeneous and honest group, who are mobilized by populist rhetoric (Mudde, 2004). Who the people are depends on context, but their conception by nature is anti-establishment (Mudde \& Rovira Kaltwasser, 2017). ${ }^{1}$ Examples of the people include the "heartland" or the "silent majority," who were mobilized during the 2016 U.S. presidential election and Brexit referendum. The elite are typically characterized as powerful and influential, but corrupt establishments in the realms of economy, culture or media, representing the enemy of the people (Mudde, 2004). Mainstream news outlets, for example, can be considered an establishment which some populists challenge.

Populism is a "thin" ideology in that it is limited unless it is connected to other beliefs (Stanley, 2008). This notion of a thin ideology indicates that core populism principals can manifest across various contexts. Specifically, the separation of society into two opposition groups and volonté générale are common to all variants of populism no matter how disparate any two populist leaders or parties are (Ivaldi, Lanzone, \& Woods, 2017; Stanley, 2008). Arguably, populism may not exist or manifest in any "pure" form; it typically attaches to other ideologies like nationalism or socialism, producing different outcomes because of the host ideology (Mudde \& Rovira Kaltwasser, 2017). Rhetoric can be considered populist as long as it includes notions of volonté générale and the Manichaean dualism between the people and elite (Stanley, 2008). Some populist movements might emphasize civil liberties or provide a voice for underserved groups (Laclau, 2005), and in other instances, populist mobilization focuses on nativism and the rejection of modernization (Rensmann, 2017). Populist politicians can be located all over the political spectrum (left-wing, right-wing, centrist, authoritarian) and across many societies such as Tony Blair, Hugo Chavez or Jean Marie Le Pen (Canovan, 2004).

The collective identity of populist movements, i.e., the "people" is a context-driven concept, but usually refers to an economic or cultural identity that is juxtaposed against some elite or ruling group (Meléndez \& Rovira Kaltwasser, 2019). This notion of the "people" is homogenized, which may have to do with the tendencies of creating ideal representations of the group - a collective identity (Gaertner et al., 1993; Simon \& Klandermans, 2001). Typically, right-wing populist movements or leaders will conceive an exclusionary conception of the people, often demarcated on ethnic or national lines (Mudde, 2007). In contrast, left-wing populist movements or leaders may sometimes emphasize ethnopopulist rhetoric, but also do include the importance of multiculturalism, and a greater emphasis on socioeconomic groups (Mudde \& Rovira Kaltwasser, 2017).

Individual-level populism can be assessed via related attitudes like trust and satisfaction with democracy and politicians (e.g., Doyle, 2011), but more recent research has shown that populist attitudes can be measured by more specific scales (e.g., Schulz et al., 2018). Though all authors apply the ideational definition of populism as described above, there are marked differences based on the empirically obtained factor structures. For example, the populism scale by Akkerman et al. (2014) incorporates anti-elitism, sovereignty of the people and the homogeneity of people into one unified construct assessed via a single scale. By contrast, the scale by Schulz et al. (2018) treats populist attitudes as a three-factor model, with subscales pertaining to anti-elitism, sovereignty of the people, and the homogeneity of people. Castanho Silva et al. (2018) also developed a three-factor model, but posited that the Manichaean view of society should be assessed via its own subscale, whereas other authors (Akkerman et al., 2014; Schulz et al., 2018) argued that this Manichaean view of society is inherent in anti-elite sentiments. Despite structural differences, these scales overlap on key features like anti-elitism (Castanho Silva, Jungkunz, Helbling, \& Littvay, 2020).

\section{Understanding Populism as a Cultural Phenomenon}

\section{Culture}

Culture represents the norms, customs, symbols and values that people within a society share (Heine, 2010). Even in homogenous societies, there are subcultures because of ecological or contextual differences such as a person's religious

1) The term anti-establishment does not suggest populist groups or movements are inherently maladaptive; anti-establishment groups can and have challenged unresponsive political elites (Laclau, 2005). 
background (Cohen, 2009). Recent research has argued that populism is in part a cultural phenomenon, and theorists have offered a number of convergent approaches in understanding populism as culture.

\section{Populism as Culture}

Populist leaders and movements do not operate within a vacuum, but rather incorporate societies' political legacies and values (Mudde \& Rovira Kaltwasser, 2017), and likewise, members of society are also embedded within their own cultural context that shapes their perceptions of the political system (e.g., Jami \& Kemmelmeier, 2021). The emergence of populism in political discourse can be tied to cultural conflict, often associated with economic changes due to globalization (Norris \& Inglehart, 2019; Rensmann, 2017). For example, some native populations are concerned about the influx of non-natives, perceived to be aided by the elite, altering their society's norms and values (Betz, 1994). Such shared sentiments foster populist subcultures, which adopt a language of "us" versus "them" to differentiate populists from other members of society like right-wing populist identifiers who consider themselves as patriots and as the "people," relative to immigrants and the "elite" (Staerklé \& Green, 2018). Moreover, the shared meaning system of the populist subculture paints political leaders and other symbols in a different light. Uyheng and Montiel (2020) noted that the political alignment within a cultural context (i.e., Philippines) can influence the social representation of populist leaders such as Rodrigo Duterte, who can be described as a "paternalistic patriot" by his supporters or as a "dictator and murderer" by his detractors. Consistent with this observation, politicians typically shift their language and rhetoric to match the populist subculture which includes moralizing issues and speaking in plain language (Ostiguy, 2017). Much of this stylistic or "performative" change is consistent with differing body language, gestures and dressing similarly to that of populist groups. This change is done to flaunt the "low" relative to the "high," that is, flaunt the people relative to the elite (Ostiguy, 2017). Arguably, the rhetorical style of populism may necessitate politicians to embed themselves within the symbolic and cultural system of populist groups in order to garner support.

\section{Populism as an Extension of the Mainstream}

Yet, populist subcultures are not a set of values or norms isolated from the rest of society; they are connected to, if not in lockstep with some mainstream values. Mudde (2010) indicated that tendencies of populism are not necessarily exclusive to a small minority nor are they alien to mainstream ideologies; instead, populist related norms are embedded in everyday attitudes and beliefs of a society. Thus, populist beliefs can reflect a society's culture, albeit a radicalized interpretation of the norms. Especially in times of economic and cultural calamities, these populist attitudes take hold in the mainstream (Guiso, Herrera, Morelli, \& Sonno, 2019; Norris \& Inglehart, 2019). From this perspective, populist ideas typically represent an amplification of beliefs that are prevalent in mainstream culture.

Though the cultural elements of populism are well documented, an important limitation of the current research is understanding the "etic" or universal elements of populism. Much of the existing research has focused on understanding the cultural correlates and manifestations of populism which tend to be "emic" or context-specific (Elchardus \& Spruyt, 2016; Uyheng \& Montiel, 2020) and limited to regions or societies in Western Europe (Betz, 1994; Staerklé \& Green, 2018).

\section{Social Axioms}

Populist attitudes might be entwined with the types of worldviews that cultural psychologists have long documented (e.g., Hofstede, 2011). People in a country typically share some assumptions about the world, called social axioms, which represent implicit expectations about themselves, society, and the spiritual world (Leung et al., 2002). They are the basic premise people rely upon to guide their everyday life (Leung \& Bond, 2008; Singelis, Hubbard, Her, \& An, 2003). Research has identified the social axioms in over 40 societies (Bond et al., 2004b), and shown that they predict several specific beliefs and behaviors like economic positions, vocational interests, and coping strategies (Bond et al., 2004b; Fasce \& Avendaño, 2020).

The social axioms framework was developed with the goal of identifying universal aspects of culturally related social beliefs with references of the social world rather than abstract ideals like social values (Leung et al., 2002; Singelis et al., 2003). Thus, social axioms can function as people's social beliefs within the context of people's everyday norms, 
but unlike other cultural approaches to populism (e.g., Staerklé \& Green, 2018; Uyheng \& Montiel, 2020) social axioms can represent broad social beliefs across cultural contexts (Leung \& Bond, 2008). Though it is clear that manifestations of populism have many commonalities over the course of history (Mudde \& Rovira Kaltwasser, 2017), much of this robustness is documented at the political level and not at the individual level. That is, the bulk of populism research has focused on politicians, political discourse, and political parties (Akkerman et al., 2014) and their similarities across space and time (Rooduijn \& Pauwels, 2011), but not on individual-level populist attitudes. The social axioms, as a set of etic dimensions, are suitable in detecting the cultural underpinnings of populism across different time and contexts.

The five individual-level axioms are social cynicism, reward for application, religiosity, social flexibility, and fate control. Social cynicism indicates people's negative evaluation of humanity like disliking certain groups or institutions or suspecting the misuse of power by others (Leung et al., 2002), and lower interpersonal trust (Singelis et al., 2003). Reward for application is the belief that hard work, knowledge, and careful preparation can lead to positive outcomes. People high in reward for application tend to support traditional values like security and conformity (Leung et al., 2002). Religiosity is the belief that spiritual entities influence the physical world, and that religious institutions positively impact society (Bond et al., 2004b). Social flexibility is the viewpoint that there are multiple solutions to issues and people change depending on the context. People with high social flexibility tend to view problem solving as a coping strategy (Bond et al., 2004b). Lastly, fate control characterizes the ongoing struggle between external forces and one's perceived ability to shift the tides in their favor.

When measured at the country-level, the social axioms represent a reduced set of two dimensions: societal cynicism and dynamic externality (Bond et al., 2004b). Similar to the thus-named dimension at the individual level, societal cynicism is the extent to which nations are distrustful of human behavior and intentions; this dimensions is related to a general expectation of negative outcomes (e.g., other's cooperation during in-group dilemmas), and suspicions of political suppression by powerful groups (Bond et al., 2004b). Dynamic externality combines elements of the other four individual-level axioms to indicate the extent to which societies as a whole are attuned to the external elements of the world (such as potential danger) and their ability to overcome such challenges.

\section{Hypotheses}

Social cynicism entails the idea that other people and institutions cannot be trusted and that their power must be reduced which may underpin the anti-establishment and mistrusting attitudes found in populism. Thus, social cynicism should predict populism and its facets (Hypothesis 1).

Reward for application taps beliefs of meritocracy and fairness and entails compromising and collaboration as conflict resolution strategies (Bond et al., 2004b; Fasce \& Avendaño, 2020). Considering that populism involves economic grievances (Guiso et al., 2019), declinism (Elchardus \& Spruyt, 2016), majoritarianism (Pappas, 2013) and skepticism toward compromising (Mudde, 2007), we expect reward for application to be inversely related to populist attitudes (Hypothesis 2).

Social flexibility describes an appreciation for the intricacies and complexities of everyday life along with divergent thinking and adjusting to new experiences. Because populism is an unconventional political style (Jagers \& Walgrave, 2007) and is related to the psychological trait of openness (Vasilopoulos \& Jost, 2020), we expected it to positively predict populist attitudes (Hypothesis 3).

Populism appeals to those individuals who feel left out of society and lack control, and who are mobilized to "take back" society from outgroups or establishments (Schwartz et al., 2020). Therefore, fate control should be negatively related to populist attitudes (Hypothesis 4).

Because societal cynicism is linked to mistrust of people and institutions (Bond et al., 2004b), it should also predict populist attitudes (Hypothesis 5). A society's general climate of societal cynicism should also amplify the effects of individual-level social cynicism, social flexibility, reward for application and fate control (Hypothesis 6). Thus, in highly cynical societies the implications of individual-level social axioms should be more pronounced. In such societies, individual-level social cynicism and social flexibility should be more likely to predict higher populist attitudes, and reward for application and fate control should predict lower populist attitudes. We did not identify a rationale as to why religiosity and dynamic externality should be related to populist attitudes and thus, make no hypotheses. 


\section{The Present Research}

Two studies examined the link between culturally-shared worldviews and populist attitudes. Study 1 employed a US sample to examine the relationship between populist attitudes and social axioms. Study 2 expanded this to a series of multi-level analyses across 33-country samples, including country-level axioms and cross-level interactions. All analyses controlled for socio-economic variables as various authors have argued that populist attitudes are linked to, if not the product of, class position or economic woes (e.g., Guiso et al., 2019).

\section{Study 1}

\section{Method}

\section{Participants}

Participants were 488 (122 men, 366 women, 5 "other") undergraduates from a western U.S. university and were compensated with course credit. Most participants were White (60\%), followed by Hispanic/Latino (18\%), Asian/Pacific Islander (14\%), Black (4\%), and "other" (4\%). The vast majority of respondents (90\%) were between the ages of 18 to 24 . About $59 \%$ of respondents' fathers and $60 \%$ of respondents' mothers completed some or college or less. Respondents' household incomes varied: less than $\$ 25,000$ or less (10\%), $\$ 25,001$ to $\$ 50,000$ (20\%), $\$ 50,001$ to $\$ 75,000$ (18\%), $\$ 75,001$ to $\$ 100,000$ (18\%), $\$ 100,001$ to $\$ 150,000(19 \%)$, and greater than $\$ 150,001$ (15\%). This sample's household income was similar to the overall US population (Statistica, 2019). The data were collected in late 2019 and early 2020.

\section{Materials and Procedures}

Participants responded on a 5-point scale, ranging from 1 strongly disbelieve to 5 strongly believe [social axioms], or 1 strongly disagree to 5 strongly agree [populist attitudes]. Participants completed all measures via an anonymous online survey implemented on Qualtrics.com. Participants provided their demographic information before completing all measures.

Populist attitudes - Populist attitudes were measured by a scale developed by Schulz et al. (2018), which consists of three facets, and can be analyzed separately or as a unified scale. The first facet captures anti-elite attitudes which describe the extent people may be dissatisfied and distrusting of politicians (e.g., "People like me have no influence on what the government does."). The second facet assessed beliefs about the sovereignty of the people which highlights the people as the central focus in politics and the demand for direct democracy (e.g., "The people should be asked whenever important decisions are taken."). Finally, the third facet taps notions about the homogeneity of the people - the belief that ordinary people are all similar and virtuous (e.g., "Ordinary people are of good and honest character.").

Social axioms - We measured the five axioms using the 39-item social axiom survey (SAS; Leung \& Bond, 2008). The social cynicism scale included 11 items (e.g., "Powerful people tend to exploit others."), reward for application scale had nine items (e.g., "Hardworking people will achieve more in the end."), religiosity inventory contained seven items (e.g., "Belief in a religion helps one understand the meaning of life."), social flexibility scale was composed of six items (e.g., "One has to deal with matters according to the specific circumstances."), and fate control inventory contained six items as well (e.g., "There are many ways for people to predict what will happen in the future.").

\section{Results}

\section{Descriptive Statistics}

Table 1 reported the descriptive statistics, intercorrelations and the reliabilities for all Study 1 variables. Cronbach's alpha was adequate for all measures, though McDonald's omega, an index for unidimensionality, was low for social cynicism and fate control. Mostly moderate correlations (smaller than $r=.30$ ) were found between all social axioms. 
The unexpectedly high correlation between reward for application and social flexibility was consistent with previous research (Singelis et al., 2003). Populist subscales were moderately to strongly correlated with social flexibility and social cynicism.

Table 1

Descriptive Statistics and Correlation Matrix (Study 1)

\begin{tabular}{|c|c|c|c|c|c|c|c|c|c|c|c|c|}
\hline Scale & $M$ & $S D$ & $\alpha$ & $\omega$ & 2 & 3 & 4 & 5 & 6 & 7 & 8 & 9 \\
\hline 1. Populism total & 3.38 & 0.53 & .72 & .67 & $.58^{* * *}$ & $.79^{* * *}$ & $.73^{* * *}$ & $.32^{* * *}$ & $.09^{\dagger}$ & $-.13^{* *}$ & $.13^{* *}$ & $.12^{* *}$ \\
\hline 2. Homogeneity & 2.73 & 0.79 & .76 & .67 & & $.12^{* * *}$ & .04 & .07 & .01 & .04 & $-.24^{* * *}$ & $.21^{* * *}$ \\
\hline 3. Sovereignty & 3.75 & 0.76 & .80 & .79 & & & $.53^{* * *}$ & $.23^{* * *}$ & .07 & $-.15^{* *}$ & $.24^{* *}$ & .03 \\
\hline 4. Anti-elitism & 3.67 & 0.71 & .59 & .48 & & & & $.38^{* * *}$ & $.12^{* *}$ & $-.17^{* \star *}$ & $.28^{* * *}$ & .00 \\
\hline 5. Cynicism & 3.23 & 0.50 & .69 & .41 & & & & & $.11^{*}$ & $-.14^{* *}$ & $.13^{* *}$ & $.34^{* * *}$ \\
\hline 6. Reward App. & 3.79 & 0.52 & .69 & .59 & & & & & & $.24^{* * *}$ & $.40^{\text {*** }}$ & $.15^{* * *}$ \\
\hline 7. Religiosity & 2.96 & 0.76 & .80 & .72 & & & & & & & -.05 & $.15^{* *}$ \\
\hline 8. Social Flexibility & 4.09 & 0.53 & .74 & .64 & & & & & & & & $-.16^{* * *}$ \\
\hline 9. Fate Control & 2.73 & 0.63 & .64 & .57 & & & & & & & & \\
\hline
\end{tabular}

${ }^{\dagger} p<.10 .{ }^{*} p<.05 .{ }^{* *} p<.01 .{ }^{* * *} p<.001$.

\section{Multiple Regression}

See Table 2 for the summary of the analyses in which we regressed populist attitudes and its facets on social axioms. We found support for Hypothesis 1: social cynicism predicted populist attitudes and two of its facets, sovereignty of the people and anti-elitism, though social cynicism was unrelated to homogeneity of the people. For Hypothesis 2, no support was found as reward for application was unrelated with populism and its facets. There was some support for Hypothesis 3 with social flexibility predicting both sovereignty of the people and anti-elitism, though it was inversely related to homogeneity of the people. Finally, we found mixed evidence to support Hypothesis 4, as fate control was inversely related with anti-elitism, but positively linked with homogeneity of the people. There were also unexpected negative relationships with religiosity and populism and two of its facets. Our measures of social class (parental education, household income) were unrelated to populist attitudes.

Table 2

Multiple Regression Predicting Populist Attitudes (Study 1).

\begin{tabular}{|c|c|c|c|c|c|c|c|c|c|c|c|c|c|c|c|c|}
\hline \multirow[b]{2}{*}{ Variable } & \multicolumn{4}{|c|}{$\begin{array}{l}\text { Populism } \\
\text { (Total) }\end{array}$} & \multicolumn{4}{|c|}{$\begin{array}{l}\text { Homogeneity } \\
\text { of the people }\end{array}$} & \multicolumn{4}{|c|}{$\begin{array}{l}\text { Sovereignty } \\
\text { of the people }\end{array}$} & \multicolumn{4}{|c|}{ Anti-Elitism } \\
\hline & $b$ & $S E$ & $\beta$ & $95 \% \mathrm{CI}$ & $b$ & $S E$ & $\beta$ & $95 \% \mathrm{CI}$ & $b$ & $S E$ & $\beta$ & $95 \% \mathrm{CI}$ & $b$ & $S E$ & $\beta$ & $95 \% \mathrm{CI}$ \\
\hline \multicolumn{17}{|l|}{ Social axioms } \\
\hline Cynicism & 0.29 & 0.05 & $.28^{* * *}$ & $.19, .38$ & 0.06 & 0.08 & .05 & $-.05, .15$ & 0.25 & 0.08 & $.17^{* * *}$ & $.07, .26$ & 0.56 & 0.07 & $.39^{* \star *}$ & $.30, .49$ \\
\hline Reward App. & 0.04 & 0.05 & .04 & $-.06, .15$ & 0.09 & 0.08 & .06 & $-.09, .10$ & -0.02 & 0.08 & -.01 & $-.11, .09$ & 0.06 & 0.07 & .04 & $-.06, .14$ \\
\hline Religiosity & -0.07 & 0.03 & $-.11^{*}$ & $-.20,-.01$ & $<0.01$ & 0.05 & $<.01$ & $-.13, .21$ & -0.13 & 0.05 & $-.13^{* *}$ & $-.22,-.03$ & -0.10 & 0.04 & $-.11^{*}$ & $-.20,-.02$ \\
\hline Social Flexibility & 0.07 & 0.05 & .07 & $-.03, .18$ & -0.35 & 0.08 & $-.23^{* \star *}$ & $-.33,-.12$ & 0.31 & 0.08 & $.21^{* * *}$ & $.11, .31$ & 0.26 & 0.07 & $.19^{* *}$ & $.09, .29$ \\
\hline Fate Control & 0.02 & 0.04 & .03 & $-.07, .13$ & 0.18 & 0.07 & $.14^{\star *}$ & $.04, .24$ & $<-0.01$ & 0.06 & $<.01$ & $-.10, .10$ & -0.11 & 0.05 & $-.10^{*}$ & $-.19,-.00$ \\
\hline \multicolumn{17}{|l|}{ Controls } \\
\hline Gender $($ Male $=0)$ & $<0.01$ & 0.06 & $<.01$ & $-.21, .21$ & -0.08 & 0.09 & -.10 & $-.32, .10$ & 0.10 & 0.08 & .14 & $-.07, .34$ & -0.02 & 0.07 & -.03 & $-.23, .16$ \\
\hline Father Ed. & 0.04 & 0.03 & $<.01$ & $-.07, .16$ & -0.01 & 0.02 & -.02 & $-.14, .10$ & 0.06 & 0.04 & .10 & $-.01, .22$ & $<0.01$ & 0.03 & .01 & $-.10, .12$ \\
\hline Mother Ed. & -0.05 & 0.02 & .04 & $-.16, .06$ & 0.01 & 0.04 & .02 & $-.10, .13$ & -0.04 & 0.04 & -.06 & $-.17, .05$ & -0.04 & 0.03 & -.07 & $-.18, .03$ \\
\hline Household & $<0.01$ & 0.01 & -.05 & $-.10, .11$ & -0.02 & 0.02 & .03 & $-.14, .08$ & -0.02 & 0.02 & -.04 & $-.15, .06$ & 0.03 & 0.02 & .09 & $-.01, .19$ \\
\hline Income & & & & & & & & & & & & & & & & \\
\hline \multicolumn{17}{|l|}{ Age Groups ${ }^{a}$} \\
\hline $25-35$ & 0.06 & 0.09 & .01 & $-.34, .36$ & -0.01 & 0.14 & -.02 & $-.34, .38$ & -0.06 & 0.13 & -.08 & $-.43, .26$ & 0.07 & 0.12 & .09 & $-.24, .42$ \\
\hline Over 36 & 0.37 & 0.14 & $1.01^{* *}$ & $.19,1.23$ & 0.23 & 0.22 & .29 & $-.24, .82$ & 0.61 & 0.20 & $.80^{* *}$ & $.29,1.32$ & 0.28 & 0.18 & .39 & $-.11, .88$ \\
\hline
\end{tabular}




\begin{tabular}{|c|c|c|c|c|c|c|c|c|c|c|c|c|c|c|c|c|}
\hline \multirow[b]{2}{*}{ Variable } & \multicolumn{4}{|c|}{$\begin{array}{l}\text { Populism } \\
\text { (Total) }\end{array}$} & \multicolumn{4}{|c|}{$\begin{array}{l}\text { Homogeneity } \\
\text { of the people }\end{array}$} & \multicolumn{4}{|c|}{$\begin{array}{l}\text { Sovereignty } \\
\text { of the people }\end{array}$} & \multicolumn{4}{|c|}{ Anti-Elitism } \\
\hline & $b$ & $S E$ & $\beta$ & $95 \% \mathrm{CI}$ & $b$ & $S E$ & $\beta$ & $95 \% \mathrm{CI}$ & $b$ & $S E$ & $\beta$ & $95 \% \mathrm{CI}$ & $b$ & $S E$ & $\beta$ & $95 \% \mathrm{CI}$ \\
\hline \multicolumn{17}{|l|}{ Race/ethnicity ${ }^{b}$} \\
\hline Asian American & $<0.01$ & 0.07 & $<.01$ & $-.28, .27$ & -0.03 & 0.11 & -.03 & $-.31, .24$ & 0.12 & 0.10 & .15 & $-.12, .42$ & -0.10 & 0.09 & -.13 & $-.39, .12$ \\
\hline African American & -0.14 & 0.12 & -.14 & $-.60, .32$ & -0.34 & 0.19 & -.42 & $-.89, .05$ & 0.07 & 0.18 & .11 & $-.36, .55$ & 0.04 & 0.16 & .06 & $-.37, .50$ \\
\hline Latinx American & 0.20 & 0.07 & .20 & $-.08, .48$ & -0.04 & 0.12 & -.05 & $-.33, .24$ & 0.32 & 0.11 & $.41^{* * * *}$ & $.14, .69$ & 0.04 & 0.10 & .05 & $-.22, .31$ \\
\hline Other & -0.23 & 0.12 & -.23 & $-.68, .23$ & -0.13 & 0.19 & -.17 & $-.64, .30$ & -0.10 & 0.18 & -.13 & $-.59, .33$ & -0.12 & 0.16 & -.17 & $-.60, .27$ \\
\hline
\end{tabular}

Note. $N=456-471$. Coefficients that are bolded are statistically significant at least at $p<.05$.

${ }^{\mathrm{a}} 24$ years or younger $=0 .{ }^{\mathrm{b}}$ White $=0$.

${ }^{\dagger} p<.10 .{ }^{*} p<.05 .{ }^{* *} p<.01 .{ }^{* * *} p<.001$.

\section{Discussion}

Study 1 found some evidence to support our hypotheses. For Hypothesis 1, we observed that most populist attitudes (except homogeneity of the people) were related to social cynicism. Perhaps people high on social cynicism endorse anti-elitism because they do not believe political and cultural establishments to have their best interests in mind, yet also endorse the sovereignty of the people dimension to combat the status quo. Other than anticipated by Hypothesis 2, reward for application was unrelated to populist attitudes. Hypothesis 3 was also supported. Aspects of populist attitudes were related to higher social flexibility, likely because of the anti-establishment nature of populism. After all, populist movements depart from mainstream politics by championing ideas that represent an unconventional political approach.

Indeed, Mudde and Rovira Kaltwasser (2017) asserted that a potential benefit of populism is that populist leaders or parties can advocate for political issues and solutions that are typically outside of the mainstream. Therefore, socially flexible people may be drawn to populism because of its novel approach to politics. However, people with high social flexibility are not drawn to all populist ideas, as social flexibility predicted lower levels of homogeneity of the people. This might be because the homogeneity of the people facet simplifies the conception of the people instead of recognizing diverse political cleavages, with individuals high in social flexibility being drawn to the latter.

We found mixed results concerning Hypothesis 4. Though lower fate control predicted anti-elitism, higher fate control was also related to homogeneity of the people; this latter relationship may have emerged because believing that non-elite people are a unified group could provide a sense of control. In other words, people with higher levels of fate control may view instances of populism as an expression of a collective identity. Yet, the relationship between low fate control and anti-elitism may indicate that people with low fate control feel powerlessness relative to the elite. There were unexpected negative correlations between religiosity and populist attitudes. Though we cannot offer a cogent explanation, it is possible that respondents viewed religion and its institutions as part of the status quo.

\section{Study 2}

Whereas the goal of Study 1 was to establish social axioms as predictors of populism, the goal of our second investigation was to replicate and expand our findings. Unlike Study 1, Study 2 used an international dataset called the "Survey of World Views" (Saucier et al., 2015) which contained 34 countries and 8,883 respondents. We sought to replicate our previous findings for social cynicism and social flexibility and submitted our hypotheses regarding fate control and reward for application to a more comprehensive test across different countries, and to test Hypothesis 5 and Hypothesis 6. All analyses controlled for parental education, and country-level economic differences: wealth and inequality. 


\section{Method}

\section{Data and Participants}

Student data were collected in 2012 from 34 countries across all major continents who were compensated with a $\$ 20$ (USD) gift card or money transfer. All respondents needed internet access in order to participate and were recruited through faculty distributed flyers. One country sample (United Arab Emirates) was removed because it included only four participants. Because we included only cases with complete data, we were only able to retain two-thirds of the participants, ranging from $47.53 \%$ (USA) to $85.56 \%$ (UK), with an average of $66.89 \%$. The final analysis sample comprised 5,837 respondents, with an average 176.9 respondents per country, ranging from 20 (Ireland) to 306 (Japan). ${ }^{2}$ Overall, this sample was approximately $60 \%$ female, with a mean age of 22.25 years $(S D=5.39)$. See the Supplementary Materials for descriptive statistics by country.

\section{Measures}

This dataset contained items for a range of measures spanning from personality, morality and beliefs (Saucier et al., 2015). Participants responded on a Likert scale, ranging from 1 strongly disbelieve to 6 strongly believe or 1 strongly disagree to 6 strongly agree. We describe the measures we used to test our hypotheses below.

Social axioms - Social axioms were measured with the SAS (Leung et al., 2002). A total of 30 items were used to tap all five social axioms. Nearly all items were identical to Study 1. Following Bond et al. (2004b), we constructed measures for societal cynicism and dynamic externality by aggregating respondents' scores for each country.

Populism - In order to measure populism, we selected items from some of Saucier's (2013) ism attitudes. The ism attitudes represent a five-factor model to describe the structure of various social attitudes (e.g., spirituality, egalitarianism). We used three items to tap anti-elitism ("The people running this country don't really care what happens to people like me"), sovereignty of the people ("I support the rights and power of the people in their struggle against the privileged elite"), and institutional trust ("I can always trust the government to do what is right"). The latter item was reverse-coded. The SWV did not include any item pertaining to the homogeneity of the people. See the Supplementary Materials for an expanded discussion of the survey items.

Individual-level covariates - In our analyses we controlled for gender, age, and parental education. Data for gender and age for different countries are summarized in Saucier et al. (2015); see the Supplementary Materials for parental education by country.

Country-level covariates - At the country level we controlled for levels of social inequality (Gini coefficient) and wealth (General Domestic Product per capita). See the Supplementary Materials for country-level details.

\section{Results}

\section{Descriptive Statistics}

Table 3a and 3b provide the descriptive statistics, reliability, and correlations for individual and country-level variables. Reliability and unidimensionality of the scales varied and unidimensionality was especially low for religiosity. Nearly all correlations were significant. Once again, the social axioms were moderately correlated with each other which is consistent with previous research (Singelis et al., 2003). The three items used to measure populist attitudes were not strongly correlated with any particular item. 
Table 3a

Descriptive Statistics and Correlation Matrix (Study 3) - Individual Level

\begin{tabular}{|c|c|c|c|c|c|c|c|c|c|c|c|c|}
\hline Scale & $M$ & $S D$ & $\alpha$ & $\omega$ & ICC & 2 & 3 & 4 & 5 & 6 & 7 & 8 \\
\hline 1. Sovereignty & 4.47 & 1.32 & & & .16 & $.16^{* * *}$ & .02 & $.14^{* * *}$ & $.13^{* * *}$ & $.07^{* * *}$ & $.18^{* * *}$ & .02 \\
\hline 2. Anti-elitism & 4.13 & 1.53 & & & .06 & & $.26^{* * *}$ & $.23^{* * *}$ & .02 & $-.10^{* * *}$ & $.06^{* * *}$ & $.04^{* *}$ \\
\hline 3. Mistrust & 4.23 & 1.52 & & & .23 & & & .02 & $-.10^{* * *}$ & $-.22^{* * *}$ & $.10^{* * *}$ & $-.21^{* * *}$ \\
\hline 4. Cynicism & 3.99 & 0.93 & .59 & .48 & .09 & & & & $.19^{* * *}$ & .01 & $.30^{* * *}$ & $.29^{* * *}$ \\
\hline 5. Reward App. & 4.76 & 0.93 & .68 & .67 & .18 & & & & & $.29^{* * *}$ & $.45^{* * *}$ & $.13^{* * *}$ \\
\hline 6. Religiosity & 3.86 & 1.26 & .69 & .03 & .22 & & & & & & $.11^{* * *}$ & $.27^{* * *}$ \\
\hline 7. Social Flexib. & 4.75 & 0.69 & .74 & .70 & .09 & & & & & & & $.09^{* * *}$ \\
\hline 8. Fate Control & 3.34 & 0.93 & .55 & .48 & .15 & & & & & & & \\
\hline
\end{tabular}

Table 3b

Descriptive Statistics and Correlation Matrix (Study 3) - Country Level

\begin{tabular}{lrrrrr}
\hline Scale & \multicolumn{1}{c}{$\boldsymbol{M}$} & \multicolumn{1}{c}{$\boldsymbol{S D}$} & \multicolumn{1}{c}{$\mathbf{2}$} & $\mathbf{3}$ & $\mathbf{4}$ \\
\hline 1. Societal Cynicism & 3.99 & 0.37 & .26 & -.31 & \multicolumn{1}{c}{.08} \\
2. Dynamic Externality & 3.86 & 0.29 & & $-.68^{* * *}$ & \multicolumn{1}{c}{$.44^{*}$} \\
3. GDP & 17645.00 & 17996.00 & & & $-.55^{* *}$ \\
4. Gini & 37.47 & 5.77 & & & \\
${ }^{\dagger} p<.10 .{ }^{*} p<.05 .{ }^{* *} p<.01 .{ }^{* * *} p<.001$. & & &
\end{tabular}

Multi-level modeling - Because individuals were nested within countries, we relied on multi-level modeling. All analysis controlled for wealth (GDP) and inequality (Gini) at the country level, and gender, age, and parental education at the individual level. Unrestricted maximum-likelihood estimation was used to estimate the multi-level models. All social axioms and country-level predictors were grand-mean centered. To be able to examine cross-level interaction effects, we modeled the effects of individual-level social axioms as random slopes, thus allowing for variation in their statistical effects across the 33 countries. The intra-class correlation (ICC) for all axioms and dependent variables were over .05, indicating substantial evidence of between-country differences (see Table 3 ).

See Table 4 for a summary of the multi-level models. Results supported Hypothesis 1 as social cynicism predicted all three dependent variables. There was some support for Hypothesis 2 in that lower reward for application was related to mistrust of government. Hypothesis 3 concerning social flexibility was also supported: higher levels of social flexibility were related to greater levels of all three outcome variables. Hypothesis 4 also received some support: lower levels of fate control predicted higher levels of mistrust of government. Finally, religiosity was negatively related to two of our outcome variables.

Results at the country-level, however, did not support Hypothesis 5 and 6. Neither the main effect for societal cynicism nor its cross-level interactions with individual-level axioms materialized. ${ }^{3}$ Unexpectedly, dynamic externality predicted greater trust in the government. There were also some effects of demographics. Lower mother's education predicted sovereignty of the people; yet, higher parental education was linked with mistrust of government, while father's education was unrelated to other populist attitudes. Poorer and less unequal countries expressed more mistrust of government.

3) We do note that, in terms of zero-order correlations, country-level social cynicism was related with country-level anti-elitism $(r=.35, p<.05)$. This finding did not hold in our multilevel regression analysis, which relied on grand-mean centering. However, with group-mean centering, there was a substantial country-level effect, see the Appendix. We chose not to report these group-centered analyses in the paper because Stankov and Saucier (2015) raised doubts about the measurement equivalence of country-level social axioms. 
Table 4

Multilevel Modeling of Populist Attitudes (Grand-Mean Centered) From Study 2

\begin{tabular}{|c|c|c|c|c|c|c|c|c|c|c|c|c|}
\hline \multirow[b]{2}{*}{ Variable } & \multicolumn{4}{|c|}{$\begin{array}{l}\text { Sovereignty } \\
\text { of the people }\end{array}$} & \multicolumn{4}{|c|}{ Anti-Elitism } & \multicolumn{4}{|c|}{ Mistrust of Government } \\
\hline & $b$ & $S E$ & $\beta$ & $95 \% \mathrm{CI}$ & $\boldsymbol{b}$ & $S E$ & $\boldsymbol{\beta}$ & $95 \% \mathrm{CI}$ & $b$ & $S E$ & $\boldsymbol{\beta}$ & $95 \% \mathrm{CI}$ \\
\hline Intercept & $4.48^{\star * *}$ & 0.06 & & & $4.23^{* * *}$ & 0.10 & & & $4.18^{* * *}$ & 0.10 & & \\
\hline \multicolumn{13}{|l|}{ Individual Level } \\
\hline Cynicism & 0.09 & 0.02 & $.07^{* * *}$ & $.03, .10$ & 0.26 & 0.03 & $.17^{* * *}$ & $.13, .21$ & 0.10 & 0.02 & $.07^{* * *}$ & $.04, .10$ \\
\hline Reward App. & 0.02 & 0.03 & .01 & $-.03, .06$ & -0.07 & 0.02 & $-.04^{\dagger}$ & $-.08, .00$ & -0.15 & 0.03 & $-.10^{* * *}$ & $-.14,-.06$ \\
\hline Religiosity & 0.01 & 0.02 & .01 & $-.02, .04$ & -0.10 & 0.02 & $-.07^{* * *}$ & $-.09,-.04$ & -0.06 & 0.02 & $-.04^{* *}$ & $-.07,-.01$ \\
\hline Social Flexibility & 0.25 & 0.02 & $.19^{* * *}$ & $.15, .23$ & 0.08 & 0.03 & $.05^{*}$ & $.01, .10$ & 0.18 & 0.03 & $.12^{* * *}$ & $.08, .16$ \\
\hline Fate Control & -0.03 & 0.02 & -.03 & $-.06, .01$ & 0.03 & 0.03 & .02 & $-.02, .06$ & -0.22 & 0.03 & $-.14^{* * *}$ & $-.18,-.11$ \\
\hline \multicolumn{13}{|l|}{ Country Level } \\
\hline Societal Cynicism & -0.03 & 0.06 & -.02 & $-.11, .06$ & 0.12 & 0.10 & .08 & $-.05, .21$ & -0.10 & 0.09 & -.06 & $-.19, .06$ \\
\hline Dynamic Externality & 0.10 & 0.07 & .07 & $-.04, .18$ & -0.10 & 0.10 & $.01^{\dagger}$ & $-.19, .06$ & -0.29 & 0.10 & $-.19^{* *}$ & $-.32,-.06$ \\
\hline \multicolumn{13}{|l|}{ Cross-Level } \\
\hline \multicolumn{13}{|l|}{ Societal Cynicism (SCY) } \\
\hline $\mathrm{SCY}^{*}$ Cynicism & $<0.01$ & 0.02 & .01 & $-.03, .03$ & -0.03 & 0.02 & -.01 & $-.05, .03$ & -0.04 & 0.02 & $-.03^{\dagger}$ & $-.05, .00$ \\
\hline SCY*Reward App. & 0.01 & 0.03 & .01 & $-.04, .05$ & 0.01 & 0.03 & .01 & $-.03, .05$ & -0.04 & 0.03 & $<.01$ & $-.04, .04$ \\
\hline SCY*Social Flex. & 0.01 & 0.03 & .01 & $-.04, .04$ & 0.05 & 0.03 & .03 & $-.01, .08$ & 0.03 & 0.03 & .02 & $-.02, .06$ \\
\hline $\mathrm{SCY}^{*}$ Fate Control & 0.01 & 0.02 & $<.01$ & $-.03, .04$ & 0.01 & 0.03 & -.02 & $-.06, .02$ & -0.02 & 0.03 & -.02 & $-.05, .02$ \\
\hline \multicolumn{13}{|l|}{ Controls } \\
\hline Gender $($ Male $=0)$ & -0.05 & 0.03 & -.04 & $-.09, .01$ & -0.12 & 0.04 & $-.08^{* *}$ & $-.13,-.03$ & 0.19 & 0.04 & $.12^{* * *}$ & $.08, .17$ \\
\hline Age & -0.02 & 0.02 & -.02 & $-.04, .01$ & -0.02 & 0.02 & .01 & $-.01, .04$ & -0.03 & 0.02 & -.02 & $-.04, .01$ \\
\hline Father Ed. & -0.01 & 0.02 & -.01 & $-.04, .02$ & -0.03 & 0.02 & -.02 & $-.05, .01$ & 0.04 & 0.02 & $.03^{*}$ & $.00, .06$ \\
\hline Mother Ed. & -0.05 & 0.02 & $-.04^{* *}$ & $-.07,-.01$ & 0.02 & 0.02 & .01 & $-.02, .04$ & 0.05 & 0.02 & $.03^{*}$ & $.00, .06$ \\
\hline GDP per cap. & -0.06 & 0.08 & -.04 & $-.16, .07$ & -0.17 & 0.10 & -.11 & $-.24, .02$ & -0.25 & 0.11 & $-.17^{*}$ & $-.30,-.03$ \\
\hline Inequality & 0.03 & 0.06 & .02 & $-.07, .11$ & -0.02 & 0.08 & -.01 & $-.12, .10$ & -0.18 & 0.09 & $-.12^{*}$ & $-.23,-.00$ \\
\hline \multicolumn{13}{|l|}{ Variance components } \\
\hline Intercept (between) & \multicolumn{4}{|c|}{0.08} & \multicolumn{4}{|c|}{0.28} & \multicolumn{4}{|c|}{0.27} \\
\hline Social Cynicism & \multicolumn{4}{|c|}{$<0.01$} & \multicolumn{4}{|c|}{0.01} & \multicolumn{4}{|c|}{0.01} \\
\hline Reward for Application & \multicolumn{4}{|c|}{0.02} & \multicolumn{4}{|c|}{0.02} & \multicolumn{4}{|c|}{0.01} \\
\hline Social Flexibility & \multicolumn{4}{|c|}{0.01} & \multicolumn{4}{|c|}{0.02} & \multicolumn{4}{|c|}{$<0.01$} \\
\hline Fate Control & \multicolumn{4}{|c|}{$<0.01$} & \multicolumn{4}{|c|}{0.02} & & & 0.01 & \\
\hline Residual & & & 1.52 & & & & 83 & & & & 1.66 & \\
\hline Model Fit & & & & & & & & & & & & \\
\hline$-2 L L$ & & & 06.42 & & & & 82.44 & & & & 38.64 & \\
\hline AIC & & & 33.27 & & & & 9.28 & & & & 65.48 & \\
\hline $\mathrm{BIC}$ & & & 38.42 & & & & 14.44 & & & & 70.21 & \\
\hline Marginal $R^{2}$ & & & 07 & & & & 97 & & & & 11 & \\
\hline Conditional $R^{2}$ & & & 13 & & & & 21 & & & & 25 & \\
\hline
\end{tabular}

Note. $N=5,837$. Coefficients that are bolded are statistically significant at least at $p<.05$.

${ }^{\dagger} p<.10 .{ }^{*} p<.05 .{ }^{* *} p<.01 .{ }^{* * *} p<.001$.

\section{Discussion}

Our second study submitted our hypotheses to a test within the context of a large cross-national dataset. As predicted by Hypothesis 1, social cynicism predicted all populist attitudes at the individual level, implying that social cynicism might be a key underpinning of populist views across the world. Thus, regardless of societal context, highly cynical people are more likely to support populist ideas. There was limited support for Hypothesis 2, as reward for application was only inversely related to mistrust of government. Those who believe society to be unfair or unmeritocratic are likely to mistrust the government. This pattern was not found in Study 1, which relied on an American sample only. Perhaps in the U.S., reward for application is not inherently antithetical to populist attitudes because cultural elements 
that emphasize meritocracy and fairness (e.g., Protestant work ethic; Furnham, 1984) are deeply imprinted in U.S. culture. ${ }^{4}$

Replicating Study 1, highly flexible people tend to entertain ideas, like populism, that are alternatives to mainstream ideas or the current political establishment. Hypothesis 4 pertaining to fate control was somewhat supported in Study 2 with low levels of fate control being associated with mistrust of government. Therefore, people who perceive a lack of control may believe that the government is not doings its part to help its citizens.

Our analysis did not yield any support for Hypothesis 5 and 6, as societal cynicism was unrelated to populist attitudes. Thus, societal-level assessments of culture may not influence individual's endorsement of populism (see $\mathrm{Na}$ et al., 2010). The finding that less unequal countries were higher in mistrust of the government does not appear to be consistent with notion that populist attitudes are rooted in the economic grievances or class anxieties. That is, our present data do not necessarily support that individuals and groups who are vulnerable to economic downturns or who are more likely to lose out in the context of economic globalization are particularly likely to embrace populist ideas (Guiso et al., 2019; Kriesi et al., 2006). At the same time, broadly consistent with Guiso et al. (2019), individuals in poorer countries were less likely to trust the government. Still, this must be considered only weak evidence given that no such effects of societal wealth materialized for anti-elitism and people's sovereignty. A limitation of Study 2 is that we lacked a suitable measure for the homogeneity of the people dimension. We were unable to confirm our Study 1 finding pertaining to this variable, which contained somewhat unexpected results.

\section{General Discussion}

This paper addressed the call by populism scholars to tackle the psychological underpinnings of populism. We do so with the social axioms - an etic and deeply entrenched cultural framework which represents the basic premise people use to understand their everyday life (Bond et al., 2004b), and like the various conceptualizations of culture, represent an implicit "blueprint" for how people behave and think within cultural contexts (Cohen, 2009). Across two studies, our results may indicate that people who endorse populist ideas are cynical of others' motivations, but they are also flexible and willing to go beyond conventional politics, and believe that society is unfair or unmeritocratic. Though people who support populism may also perceive a lack of control, this notion of a collective identity, assessed with the homogeneity of the people scale in Study 1, was related to greater fate control. Thus, a strong collective identity may help some people regain a sense of being in charge of their own lives. This pattern of low fate control is likely related to the perception of being left behind and treated unfairly by society (Elchardus \& Spruyt, 2016). Conversely, high cynicism and high flexibility may relate to anti-elite conspiratorial sentiments (Castanho Silva, Vegetti, \& Littvay, 2017), as anti-elite conspiratorial thinking does include a negative expectation of institutions and is typically a fringe or alternative social belief.

The present research was not able to detect predictors of differences between societies. Thus, at least in the present data, the characteristics of a country's culture did not seem to relate to the prevalence of populist attitudes. For many, this observation may not be surprising as it confirms that country-level differences in attitudes and values are often quite small and surprisingly hard to detect (e.g., Fischer \& Schwartz, 2011; Peng, Nisbett, \& Wong, 1997; Saucier et al., 2015). On the one hand, the absence of our being able to predict which countries are high and low in populism might give us pause, simply because it suggests that many different countries are susceptible to populist shifts. It might be hard for social scientists to anticipate which countries are more or less receptive to populist ideas. On the other hand, with none of our hypotheses concerning social axioms predicting populism being borne out at the country level, we are reminded that modern societies are heterogeneous and diverse. Populist attitudes may be much more prevalent among certain subcultures within a broader society (e.g., Ostiguy, 2017; Uyheng \& Montiel, 2020). Rather than engaging in between-country comparisons, the analyst's task might therefore be to identify the different subcultures within the same society, and possibly relate any cultural differences to the presence and strength of these subcultures. Though at

4) Separate analyses of the Study 2 subsample from the U.S. did corroborate that lower reward for application does not predict populist attitudes $(n=201, p$ $>$.12) for all three dependent variables. As we offer this speculation, we recognize that reward application was not involved in any cross-level interaction. 
the present time we lack a cogent explanation, we speculate that some of our unexpected findings, such as the link between low religiosity and populist attitudes, may be indicative of such subcultures.

A strength of this paper is the replicability of our findings across different countries and times. The Study 2 data were collected in 2012, and Study 1 data were acquired in 2019 and 2020; that is, our data come from periods prior to and during the presidency of Donald Trump in the U.S. In 2012, a populist like Trump was hard to imagine in the White House. In other words, these robust findings emerged during what were arguably different phases of U.S. and global politics. At a much more general level, we believe that these findings speak to Mudde and Rovira Kaltwasser's (2017) contention that populism is enduring because it can flexibly attach to various ideologies, among politicians or parties. Although the timeframe of the present two studies is limited, it appears that the cultural underpinnings of populist attitudes at the individual-level are also robust over time (cf. Rooduijn \& Pauwels, 2011).

\section{Limitations}

As with any other studies, there are limitations. First, we relied exclusively on student data. It is unclear if our findings obtained with student data would also emerge in nationally representative samples. Vasilopoulos and Jost (2020) found that openness to experience-a construct conceptually similar to aspects of social flexibility- predicts populist attitudes in a French random sample; hence, there is reason for optimism. Although Straus (2009) demonstrated that student data do accurately reflect between-country differences, a much more comprehensive international test using representative data should be conducted.

Second, all of our analyses addressed populist attitudes in a way that does not classify or divide individuals into populists and non-populists. This is critical in light of recent work which argued that populism is not merely the sum of its parts: rather than individuals falling high or low on a specific attitudinal continuum, Wuttke, Schimpf, and Schoen (2020) argued that a legitimate classification of a respondent as "populist" requires them to be high on all relevant dimensions of populist attitudes. Because of our examination of the cultural predictors only examines individual dimensions of populist attitudes, we do capture necessary conditions of populism (i.e., high endorsement of specific attitudes), but do not address whether individuals endorse the entire constellation of relevant attitudes.

Another weakness is that we used items from Saucier's (2013) isms scales which were not originally meant to tap populism attitudes. Yet, related attitudinal questions that were not originally intended to measure populism can still yield critical findings. There are numerous examples in the populism literature where research relied on single items or related attitudes to asses populism like social values (Norris \& Inglehart, 2019), political trust (Geurkink, Zaslove, Sluiter, \& Jacobs, 2020) and satisfaction with politicians (Doyle, 2011). Importantly, our Study 2 results were consistent with Study 1 findings, which used a multifaceted scale (Schulz et al., 2018). Still, our measures of government mistrust may not be sufficiently coherent with other populist attitudes to be considered part of them. Geurkink et al. (2020) found that, although populist attitudes overlap with constructs like mistrust (e.g., high correlations), there are differences in explanatory power. For instance, compared to "people-centered" populist attitudes and anti-elitism, political trust was a much weaker predictor of voting preferences. In short, even though our use of specific items of the isms scale (Saucier, 2013) should be treated with caution, results involving these items can still shed light onto the social psychology of populism.

Finally, our use of survey data does not allow for any causal inferences. Even though it is possible that cultures can render a population to be more prone to populist ideas, an alternate account would be that individuals who endorse populist attitudes tend to create a climate of cynicism, flexibility, low perceived control and perceived unfairness. That is, the prevalence of populist attitudes may influence a society's culture to contain norms that include mistrusting institutions and the government, seeking alternatives to the current status quo, and believing that society is falling apart. Whereas we consider it more plausible that existing societal cultures help shape populist ideas and movements than the reverse, we concede that only a systematic long-term study might be able to discern any insights into causal processes (see Bell, Johnston, \& Jones, 2015; Kusano \& Kemmelmeier, 2021, and Zyphur et al., 2020, for empirical approaches to causal processes in cross-national longitudinal data). 


\section{Implications}

We surmise that our study points to a "cultural vulnerability" that facilitates the receptivity to an emergence of populist sentiments. Put simply, some people are more open to populist ideas than others. We readily acknowledge that we found little in terms of cross-cultural differences; that is, at the present time we have little justification to argue, at least based on the college student data examined here, that entire countries are more vulnerable to populism than others. However, as already alluded to above, the absence of such country-level effects points to the presence of subgroups within every single country that are more vulnerable to populist sentiments than their peers. The fact that social axioms predicted populist attitudes across countries (without this predictive relationship being moderated by country-level characteristics) could be seen as indicators of an unknown reservoir of individuals who might embrace populism if circumstances present themselves. In this regard, it is critical to acknowledge that culture is not necessarily reflected in national-level differences. It might equally result in group differences within the same society that are shaped by religion, ethnicity, social class, language, or political subcultures, to name only a few (e.g., Cohen, 2009; Coon \& Kemmelmeier, 2001; Kemmelmeier \& Jami, 2021; Malka, 2014; Stephens, Markus, \& Phillips, 2014). Consistent with this multifaceted nature of culture, social axioms are embedded in the social worlds that individuals' experience in their respective societies, and reflect the social, economic and political realities that they face on a day-to-day basis (Fasce \& Avendaño, 2020; Leung et al., 2002). Social axioms may dispose individuals to respond to changes in their social world. For instance, when significant disruptions of the social order or a decline in societal well-being occurs, such as political corruption or economic crises, a society with many highly cynical and highly flexible people, as those with many individuals low in reward for application and fate control, may be more likely to mobilize in response. In this sense, the emergence of populism and populist attitudes may be considered a culturally-driven response to an everchanging social world, with social axioms being involved in determining the nature of the response.

This conception, however, makes clear that it is not necessarily useful to think about the emergence of populism as a group of populist individuals seeking power and prominence in a society. If the emergence of populism constitutes a response to social changes and issues, then, as suggested by Mudde and Rovira Kaltwasser (2017), "practitioners and scholars should focus more on the message than the messenger... and seriously examine the extent to which the proposed policies have merit within a liberal democratic regime" (p. 118). That is, though rooted in the responses of individuals who might be particularly receptive to populist ideas, analysts cannot limit themselves to the attitudes and behaviors of individuals, but must focus on the social concerns that may have occasioned the emergence of populist ideas. In turn, addressing societal woes within the liberal democratic system are likely to attenuate the influence of demagogues like Donald Trump, Rodrigo Duterte, or Jair Bolsonaro.

As a social and cultural response to social changes, populist ideas may not necessarily be maladaptive; emphasized by various scholars, populism can be a force for justice and a corrective factor for democracy (Andreucci, 2019; Laclau, 2005). Broadly speaking, populism can give voice to groups who are unrepresented, increase political participation, and increase the accountability of political elites. In an illustrative example, Andreucci (2019) argued that Evo Morales' populism helped develop a collective identity for the indigenous population of Bolivia which led to previously disenfranchised members of society to mobilize and build a transformative style of politics against the current regime. Morales, being the first indigenous president of Bolivia, fostered hope for future representation for the previously underserved indigenous voters.

Overall, the cultural underpinnings that might make some people receptive to populism can also galvanize protest, and promote progress and equality against an unfair political system (Laclau, 2005). At the same time, social problems must be addressed by policy makers in order curtail the more maladaptive manifestations of populism. These include, foremost, the emergence of authoritarian leaders, who claim to champion the disfranchised, promising to address their concerns, only to erode the liberal democratic framework. Hence, these particular social axioms investigated in the present study, may reflect a latent risk for any democratic political system.

This study opens up some exciting new research questions. For instance, is the link between populist attitudes and culture systematically moderated by controversial situations (e.g., elections, referendums, scandals)? Moreover, it is not obvious if the same social axioms also predict behavioral manifestations of populism like protest mobilization or voting. We hope to answer these questions in the future. 
Funding: The authors have no funding to report.

Acknowledgments: We gratefully acknowledge comments of Jesse Acosta and Kodai Kusano on an early draft of this paper.

Competing Interests: The authors have declared that no competing interests exist.

\section{Supplementary Materials}

Expanded discussion of Study 2 items, country-level descriptive statistics, and multilevel modeling with group-mean centered predictors (for access see Index of Supplementary Materials below).

\section{Index of Supplementary Materials}

Jami, W. A., \& Kemmelmeier, M. (2021). Supplementary materials to "The social axioms of populism: Investigating the relationship between culture and populist attitudes" [Additional information]. PsychOpen GOLD. https://doi.org/10.23668/psycharchives.5067

\section{References}

Abromeit, J. (2017). A critical review of recent literature on populism. Politics and Governance, 5(4), 177-186. https://doi.org/10.17645/pag.v5i4.1146

Akkerman, A., Mudde, C., \& Zaslove, A. (2014). How populist are the people? Measuring populist attitudes in voters. Comparative Political Studies, 47(9), 1324-1353. https://doi.org/10.1177/0010414013512600

Andreucci, D. (2019). Populism, emancipation, and environmental governance: Insights from Bolivia. Annals of the American Association of Geographers, 109(2), 624-633. https://doi.org/10.1080/24694452.2018.1506696

Bell, A., Johnston, R., \& Jones, K. (2015). Stylised fact or situated messiness? The diverse effects of increasing debt on national economic growth. Journal of Economic Geography, 15(2), 449-472. https://doi.org/10.1093/jeg/lbu005

Betz, H. G. (1994). Radical right-wing populism in western Europe. New York, NY, USA: Macmillan.

Bond, M. H., Leung, K., Au, A., Tong, K.-K., de Carrasquel, S. R., Murakami, F., . . Lewis, J. R. (2004a). Culture-level dimensions of social axioms and their correlates across 41 cultures. fournal of Cross-Cultural Psychology, 35(5), 548-570. https://doi.org/10.1177/0022022104268388

Bond, M. H., Leung, K., Au, A., Tong, K.-K., \& Chemonges-Nielson, Z. (2004b). Combining social axioms with values in predicting social behaviours. European fournal of Personality, 18(3), 177-191. https://doi.org/10.1002/per.509

Canovan, M. (2004). Populism for political theorists? fournal of Political Ideologies, 9(3), 241-252. https://doi.org/10.1080/1356931042000263500

Castanho Silva, B., Andreadis, I., Anduiza, E., Blanuša, N., Morlet Corti, Y., Delfino, G., Rico, G., ... Littvay, L. (2018). Public opinion surveys: A new scale. In K. A. Hawkins, R. E. Carlin, L. Littvay, \& C. Rovira Kaltwasser (Eds.), The ideational approach to populism: Concept, theory and analysis (pp. 150-177). London, United Kingdom: Routledge.

Castanho Silva, B., Jungkunz, S., Helbling, M., \& Littvay, L. (2020). An empirical comparison of seven populist attitudes scales. Political Research Quarterly, 73(2), 409-424. https://doi.org/10.1177/1065912919833176

Castanho Silva, B., Vegetti, F., \& Littvay, L. (2017). The elite is up to something: Exploring the relation between populism and belief in conspiracy theories. Schweizerische Zeitschrift für Politikwissenschaft, 23(4), 423-443. https://doi.org/10.1111/spsr.12270

Cohen, A. B. (2009). Many forms of culture. The American Psychologist, 64(3), 194-204. https://doi.org/10.1037/a0015308

Coon, H. M., \& Kemmelmeier, M. (2001). Cultural orientations in the United States: (Re-) examining differences among ethnic groups. Journal of Cross-Cultural Psychology, 32(3), 348-364. https://doi.org/10.1177/0022022101032003006

Doyle, D. (2011). The legitimacy of political institutions: Explaining contemporary populism in Latin America. Comparative Political Studies, 44(11), 1447-1473. https://doi.org/10.1177/0010414011407469 
Elchardus, M., \& Spruyt, B. (2016). Populism, persistent republicanism and declinism: An empirical analysis of populism as a thin ideology. Government and Opposition, 51(1), 111-133. https://doi.org/10.1017/gov.2014.27

Fasce, A., \& Avendaño, D. (2020). Opening the can of worms: A comprehensive examination of authoritarianism. Personality and Individual Differences, 163, 597-613. https://doi.org/10.1016/j.paid.2020.110057

Fischer, R., \& Schwartz, S. (2011). Whence differences in value priorities? Individual, cultural, or artifactual sources. fournal of CrossCultural Psychology, 42(7), 1127-1144. https://doi.org/10.1177/0022022110381429

Furnham, A. (1984). The Protestant work ethic: A review of the psychological literature. European fournal of Social Psychology, 14(1), 87-104. https://doi.org/10.1002/ejsp.2420140108

Gaertner, S. L., Dovidio, J. F., Anastasio, P. A., Bachman, B. A., \& Rust, M. C. (1993). The common ingroup identity model: Recategorization and the reduction of intergroup bias. European Review of Social Psychology, 4(1), 1-26. https://doi.org/10.1080/14792779343000004

Geurkink, B., Zaslove, A., Sluiter, R., \& Jacobs, K. (2020). Populist attitudes, political trust, and external political efficacy: Old wine in new bottles? Political Studies, 68(1), 247-267. https://doi.org/10.1177/0032321719842768

Guiso, L., Herrera, H., Morelli, M., \& Sonno, T. (2019). Global crises and populism: The role of Eurozone institutions. Economic Policy, 34(97), 95-139. https://doi.org/10.1093/epolic/eiy018

Hawkins, K. A., \& Rovira Kaltwasser, C. (2017). The ideational approach to populism. Latin American Research Review, 52(4), 513-528. https://doi.org/10.25222/larr.85

Heine, S. J. (2010). Cultural psychology. In D. T. Gilbert, S. Fiske, \& G. Lindzey (Eds.), Handbook of social psychology (5th ed., pp. 14231464). Hoboken, NJ, USA: Wiley.

Hofstede, G. (2011). Culture's consequences. Thousand Oaks, CA, USA: SAGE.

Ivaldi, G., Lanzone, M. E., \& Woods, D. (2017). Varieties of populism across a left-right spectrum: The case of the Front National, the Northern League, Podemos and Five Star Movement. Schweizerische Zeitschrift für Politikwissenschaft, 23(4), 354-376. https://doi.org/10.1111/spsr.12278

Jagers, J., \& Walgrave, S. (2007). Populism as political communication style: An empirical study of political parties' discourse in Belgium. European fournal of Political Research, 46(3), 319-345. https://doi.org/10.1111/j.1475-6765.2006.00690.x

Jami, W. A., \& Kemmelmeier, M. (2021). Remnants of Communism and present-day inequality. Cross-Cultural Research, 55(1), 58-91. https://doi.org/10.1177/1069397120957293

Kemmelmeier, M., \& Jami, W. A. (2021). Mask wearing as cultural behavior: An investigation across 45 U.S. states during the COVID-19 pandemic. Frontiers in Psychology, 12, Article 648692 https://doi.org/10.3389/fpsyg.2021.648692

Kriesi, H., Grande, E., Lachat, R., Dolezal, M., Bornschier, S., \& Frey, T. (2006). Globalization and the transformation of the national political space: Six European countries compared. European fournal of Political Research, 45(6), 921-956. https://doi.org/10.1111/j.1475-6765.2006.00644.x

Kusano, K., \& Kemmelmeier, M. (2021). Cultural change through niche construction: A multilevel approach to investigate the interplay between cultural change and infectious disease. The American Psychologist. Advance online publication. https://doi.org/10.1037/amp0000860

Laclau, E. (2005). On populist reason. London, United Kingdom: Verso.

Leung, K., \& Bond, M. H. (2008). Psycho-logic and eco-logic: Insights from social axiom dimensions. In F. van de Vijver, D. van Hemert, \& Y. Poortinga (Eds.), Individuals and cultures in multilevel analysis (pp. 199-219). Mahwah, NJ, USA: Erlbaum.

Leung, K., Bond, M. H., de Carrasquel, S. R., Muñoz, C., Hernández, M., Murakami, F., . . Singelis, T. M. (2002). Social axioms: The search for universal dimensions of general beliefs about how the world functions. fournal of Cross-Cultural Psychology, 33(3), 286-302. https://doi.org/10.1177/0022022102033003005

Malka, A. (2014). Political culture and democracy. In A. B. Cohen (Ed.), Culture reexamined: Broadening our understanding of social and evolutionary influences (pp. 129-153). Washington, DC, USA: American Psychological Association.

Marchlewska, M., Cichocka, A., Panayiotou, O., Castellanos, K., \& Batayneh, J. (2018). Populism as identity politics: Perceived ingroup disadvantage, collective narcissism, and support for populism. Social Psychological \& Personality Science, 9(2), 151-162. https://doi.org/10.1177/1948550617732393

Meléndez, C., \& Rovira Kaltwasser, C. (2019). Political identities: The missing link in the study of populism. Party Politics, 25(4), 520-533. https://doi.org/10.1177/1354068817741287

Mudde, C. (2004). The populist zeitgeist. Government and Opposition, 39(4), 541-563. https://doi.org/10.1111/j.1477-7053.2004.00135.x 
Mudde, C. (2007). Populist radical right parties in Europe. Cambridge, United Kingdom: Cambridge University Press.

Mudde, C. (2010). The populist radical right: A pathological normalcy. West European Politics, 33(6), 1167-1186. https://doi.org/10.1080/01402382.2010.508901

Mudde, C., \& Rovira Kaltwasser, C. (2017). Populism: A very short introduction. Oxford, United Kingdom: Oxford University Press.

Na, J., Grossmann, I., Varnum, M. E. W., Kitayama, S., Gonzalez, R., \& Nisbett, R. E. (2010). Cultural differences are not always reducible to individual differences. Proceedings of the National Academy of Sciences of the United States of America, 107(14), 6192-6197. https://doi.org/10.1073/pnas.1001911107

Norris, P., \& Inglehart, R. (2019). Cultural backlash: Trump, Brexit, and authoritarian populism. Cambridge, United Kingdom: Cambridge University Press.

Ostiguy, P. (2017). Populism: A socio-cultural approach. In C. Rovira Kaltwasser, P. Taggart, P. Ochoa Espejo, \& P. Ostiguy (Eds.), The Oxford handbook of populism (pp. 73-97). Oxford, United Kingdom: Oxford University Press.

Pappas, T. S. (2013). Why Greece failed. Journal of Democracy, 24(2), 31-45. https://doi.org/10.1353/jod.2013.0035

Peng, K., Nisbett, R. E., \& Wong, N. Y. C. (1997). Validity problems comparing values across cultures and possible solutions. Psychological Methods, 2(4), 329-344. https://doi.org/10.1037/1082-989X.2.4.329

Rensmann, L. (2017). The noisy counter-revolution: Understanding the cultural conditions and dynamics of populist politics in Europe in the digital age. Politics and Governance, 5(4), 123-135. https://doi.org/10.17645/pag.v5i4.1123

Rooduijn, M. (2019). State of the field: How to study populism and adjacent topics? A plea for both more and less focus. European Journal of Political Research, 58(1), 362-372. https://doi.org/10.1111/1475-6765.12314

Rooduijn, M., \& Akkerman, T. (2017). Flank attacks: Populism and left-right radicalism in Western Europe. Party Politics, 23(3), 193-204. https://doi.org/10.1177/1354068815596514

Rooduijn, M., \& Pauwels, T. (2011). Measuring populism: Comparing two methods of content analysis. West European Politics, 34(6), 1272-1283. https://doi.org/10.1080/01402382.2011.616665

Saucier, G. (2013). Isms dimensions: Toward a more comprehensive and integrative model of belief-system components. fournal of Personality and Social Psychology, 104(5), 921-939. https://doi.org/10.1037/a0031968

Saucier, G., Kenner, J., Iurino, K., Bou Malham, P., Chen, Z., Thalmayer, A. G., . . Altschul, B. (2015). Cross-cultural differences in a global "survey of world views.". Journal of Cross-Cultural Psychology, 46(1), 53-70. https://doi.org/10.1177/0022022114551791

Schulz, A., Müller, P., Schemer, C., Wirz, D. S., Wettstein, M., \& Wirth, W. (2018). Measuring populist attitudes on three dimensions. International fournal of Public Opinion Research, 30(2), 316-326. https://doi.org/10.1093/ijpor/edw037

Schwartz, C., Simon, M., Hudson, D., \& van-Heerde-Hudson, J. (2020). A populist paradox? How Brexit softened anti-immigrant attitudes. British fournal of Political Science, 51(3), 1160-1180. https://doi.org/10.1017/S0007123419000656

Simon, B., \& Klandermans, B. (2001). Politicized collective identity: A social psychological analysis. The American Psychologist, 56(4), 319-331. https://doi.org/10.1037/0003-066X.56.4.319

Singelis, T. M., Hubbard, C., Her, P., \& An, S. (2003). Convergent validation of the social axioms survey. Personality and Individual Differences, 34(2), 269-282. https://doi.org/10.1016/S0191-8869(02)00043-0

Staerklé, C., \& Green, E. G. T. (2018). Right-wing populism as a social representation: A comparison across four European countries. fournal of Community \& Applied Social Psychology, 28(6), 430-445. https://doi.org/10.1002/casp.2369

Stankov, L., \& Saucier, G. (2015). Social axioms in 33 countries: Good replicability at the individual but less so at the country level. fournal of Cross-Cultural Psychology, 46(2), 296-315. https://doi.org/10.1177/0022022114558333

Stanley, B. (2008). The thin ideology of populism. Journal of Political Ideologies, 13(1), 95-110. https://doi.org/10.1080/13569310701822289

Statistica. (2019). Number of households in the United States by household income in 2019. Retrieved from https://www.statista.com/statistics/183807/number-of-households-by-household-income-2009

Stephens, N. M., Markus, H. R., \& Phillips, L. T. (2014). Social class culture cycles: How three gateway contexts shape selves and fuel inequality. Annual Review of Psychology, 65, 611-634. https://doi.org/10.1146/annurev-psych-010213-115143

Straus, M. A. (2009). The national context effect: An empirical test of the validity of cross-national research using unrepresentative samples. Cross-Cultural Research, 43(3), 183-205. https://doi.org/10.1177/1069397109335770

Uyheng, J., \& Montiel, C. J. (2020). Cognitive polyphasia in a Global South populist democracy: Mapping social representations of Duterte's regime in the Philippines. Fournal of Social and Political Psychology, 8(1), 30-52. https://doi.org/10.5964/jspp.v8i1.1119 
Vasilopoulos, P., \& Jost, J. T. (2020). Psychological similarities and dissimilarities between left-wing and right-wing populists: Evidence from a nationally representative survey in France. Journal of Research in Personality, 88, Article 104004. https://doi.org/10.1016/j.jrp.2020.104004

Wuttke, A., Schimpf, C., \& Schoen, H. (2020). When the whole is greater than the sum of its parts: On the conceptualization and measurement of populist attitudes and other multidimensional constructs. The American Political Science Review, 114(2), 356-374. https://doi.org/10.1017/S0003055419000807

Zyphur, M. J., Allison, P. D., Tay, L., Voelkle, M. C., Preacher, K. J., Zhang, Z., . . Diener, E. (2020). From data to causes I: Building a general cross-lagged panel model (GCLM). Organizational Research Methods, 23(4), 651-687.

https://doi.org/10.1177/1094428119847278 